\title{
Correction to: Three-Dimensional Instability of Shock-Wave/ Boundary-Layer Interaction for Rocket Engine Nozzle Applications
}

\author{
A. Sansica, J.-Ch. Robinet, Eric Goncalves, and J. Herpe
}

\section{Correction to:}

Chapter 67 in: A. Sasoh et al. (eds.), 31st International

Symposium on Shock Waves 2,

https://doi.org/10.1007/978-3-319-91017-8_67

The original version of the book was inadvertently published with incorrect sequence of authors. The correct sequence of authors has now been corrected as

“A. Sansica, J.-Ch. Robinet, Eric Goncalves, and J. Herpe”.

The updated online version of this chapter can be found at

https://doi.org/10.1007/978-3-319-91017-8_67 